\title{
CONSERVAÇÃO DE ÁGUA EM EDIFICAÇÕES UNIVERSITÁRIAS. FATORES QUE INFLUENCIAM O CONSUMO E CRITÉRIOS PARA SUA AVALIAÇÃO: COMPARAÇÃO DE TRÊS UNIDADES DA UFBA.
}

\author{
WATER CONSERVATION IN UNIVERSITY BUILDINGS. FACTORS THAT INFLUENCE \\ CONSUMPTION AND CRITERIA FOR THEIR EVALUATION: COMPARISON OF THREE UNITS \\ OF UFBA.
}

Tainá Rosário Santana Cazaes

Graduanda em Engenharia Sanitária e Ambiental, Universidade Federal Da Bahia. (taina rosario@hotmail.com)

Raynara Guimarães Cruz

Graduanda em Engenharia Sanitária e Ambiental, Universidade Federal Da Bahia. (raynara-cruz@hotmail.com)

\section{Asher Kiperstok First}

PhD em Engenharia Química/Tecnologias Ambientais, University of Manchester / Institute of Science and Technology. Universidade Federal Da Bahia / Departamento de Engenharia Ambiental. (asher@ufba.br)

Maria do Socorro Gonçalves

Mestre em Engenharia Sanitária e Ambiental, Universidade Federal Da Bahia. (mariagon@ufba.br)

\section{Resumo}

Programas de conservação de água em universidades esbarram em diversas dificuldades, que vão desde a avaliação do desempenho destas até a implementação de medidas necessárias para a sua melhoria. Tal avaliação se refere às características das edificações e das comunidades usuárias, bem como à qualidade da gestão, as quais agregam uma grande quantidade de variáveis que dificultam a comparação do desempenho dessas instituições, seja entre elas, seja entre as Unidades que as conformam. Este trabalho procura contribuir para o esclarecimento dos fatores que concorrem para interpretar o consumo de água de prédios universitários, a partir de estudos desenvolvidos na Universidade Federal da Bahia. As Unidades acadêmicas praticam consumos específicos bastante díspares, que precisam ser melhor entendidos para que se possam orientar ações de conservação de água. A percepção do consumo de água por parte da comunidade usuária é apontada como um dos principais fatores que definem o desempenho de uma edificação. Neste trabalho, se compara o consumo de três Unidades, considerando-se alguns fatores, como a adoção de medidas que permitem uma melhor percepção do consumo, assim como as semelhanças e diferenças entre elas. Observaram-se consumos per capita entre 9 e $16 \mathrm{~L} / \mathrm{hab}$.dia, o que em si já aponta para a necessidade de uma reflexão sobre os tradicionais parâmetros de consumo utilizados no projeto destes tipos de edificações.

Palavra-chave: conservação de água, universidades, indicadores de consumo.

\section{Abstract}

Water conservation programs in universities face several difficulties that go from their performance assessment up to the implementation of the necessary measures to promote it. The buildings characteristics, as well as those of their user's community and management quality, include a large quantity of variables that make difficult to compare their performance, either between universities as a whole or academic premises, between them. This works intends to contribute to clarify the factors that help interpretation of water consumption in university buildings, based on research work developed by the Federal University of Bahia (UFBA). Perception of water consumption by the user's community, has been identified as one of the main factors that define the premises performance. In this work the consumption of three units is compared, considering factors such as adoption of actions to increase water consumption perception by users, as well as, similarities and differences between them. Per capita consumptions vary between 9 and 16 Litres per capita per day (Lpdc). These values show that it is necessary to question the values that are traditionally adopted to estimate water demand in buildings during the design of hydraulic installations. 
Keywords: Water conservation, university premises, consumption indicators.

\section{INTRODUÇÃO}

Neste artigo, se apresentam alguns dos resultados obtidos a partir do Programa Aguapura, desenvolvido no Departamento de Engenharia Ambiental da UFBA e que se destina ao incentivo do uso racional da água na UFBA, sendo iniciado em 2001. Dentre as ações realizadas pelo Programa, estão varreduras e pequenos consertos nos equipamentos das Unidades e 0 monitoramento diário do consumo.
O Programa contribuiu para uma redução significativa do consumo de água de $36.000 \mathrm{~m}^{3}$ mês ${ }^{-1}$ para $24.000 \mathrm{~m}^{3}$ mês $^{-1}$, mesmo tendo vivenciado o maior crescimento de suas instalações entre 2009 e 2012, devido ao Programa de Expansão das Universidades Federais, REUNI. A partir de 2014, se observa uma tendência à estabilização do consumo. A Figura 1 apresenta o consumo global da UFBA entre 1998 e 2018, em m³ mês ${ }^{-1}$, e indica também alguns marcos importantes para a sua compreensão.

Figura 1 - Evolução do consumo da UFBA

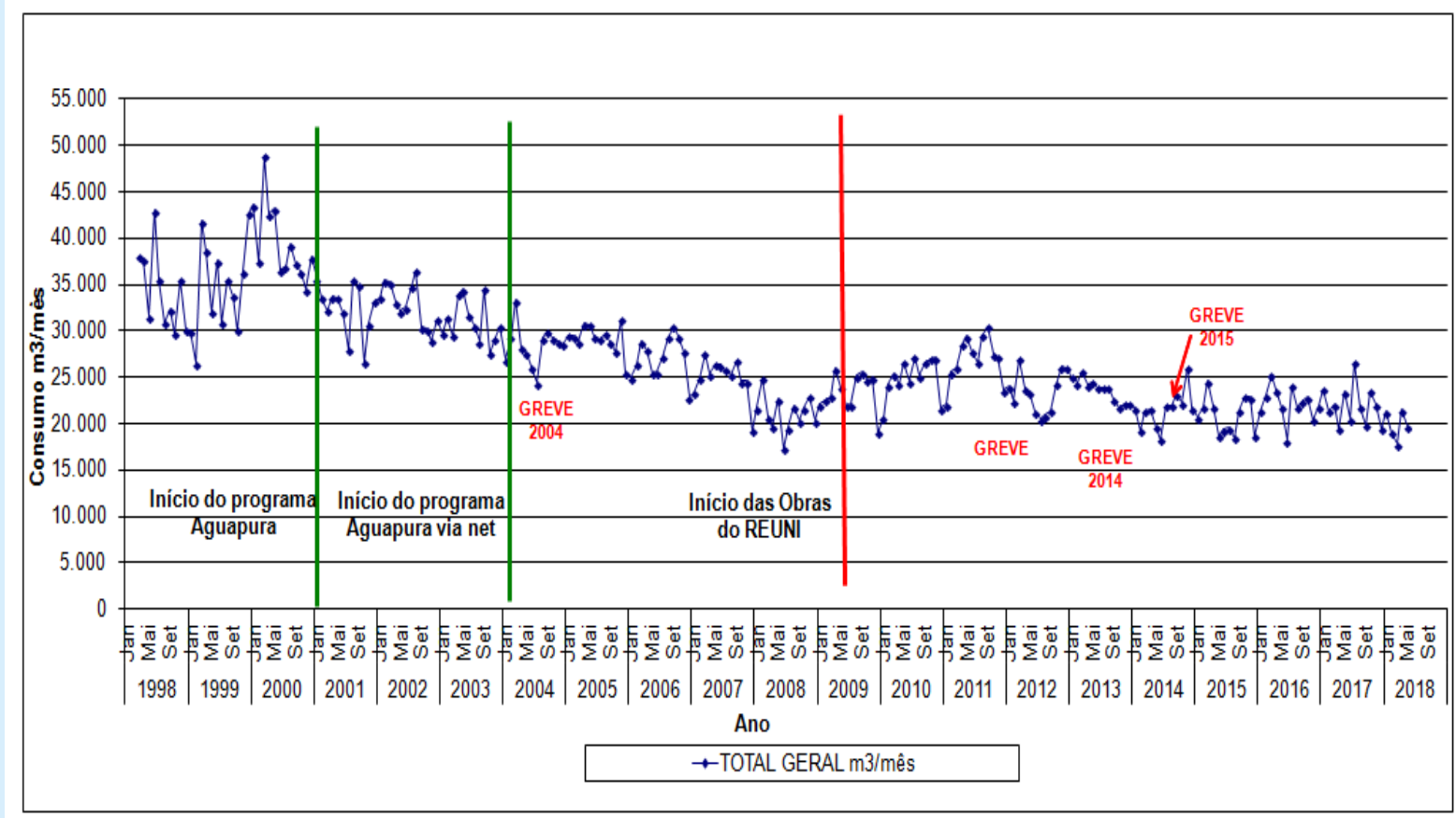

Fonte: AGUAPURA (www.teclim.ufba.br/aguapura, 2018).

A redução do consumo global da UFBA guarda uma forte relação com o desenvolvimento do Programa Aguapura. Nos anos de 1998 a 2000, que corresponde ao período anterior à implantação do Programa, a Universidade apresentava um consumo médio mensal de $36.384 \mathrm{~m}^{3} / \mathrm{mês}$. De 2001 a 2003, com a participação de uma equipe pequena de manutenção, mas, antes da implantação do monitoramento diário do consumo em algumas Unidades, o consumo médio mensal da UFBA passou para $31.125 \mathrm{~m}^{3} \mathrm{mês}^{-1}$, ou seja, houve uma redução de aproximadamente $15 \%$.
De 2004, quando foi implantado o Sistema Vianet ${ }^{1}$ (www.teclim.ufba.br/aguapura), até 2008, ano que antecede às obras da Reestruturação e Expansão das Universidades Federais (REUNI), o consumo foi reduzido ainda mais, atingindo o valor médio de $26.214 \mathrm{~m}^{3}$ mês $^{-1}$, ou seja, uma diminuição de aproximadamente $16 \%$, totalizando uma redução de 31\% para o período 2001-2008.

A partir de 2009, iniciam-se as obras do REUNI na UFBA, período em que, conforme apresentado por Maranhão et al. (2014), ocorreu um expressivo aumento no número de cursos de

1 Plataforma online que permite a todos os usuários de um edifício acompanhar o seu consumo de água diariamente. 
graduação, mestrado e doutorado, assim como contratação de novos professores. Mesmo com a expansão populacional da instituição, passando de uma média de 30.552 pessoas no período de 1999 a 2008 para 40.953 pessoas de 2009 a 2012, o consumo médio não aumentou em comparação à média do período anterior, apresentando um valor de $24.732 \mathrm{~m}^{3}$ mês $^{-1}$.

No ano de 2013, correspondente à entrega das construções e reformas nos prédios, o consumo médio foi de $23.701 \mathrm{~m} 3 / \mathrm{mês}$. Nos anos de 2014 a 2017, conforme representado na Figura 2, observa-se uma estabilização do consumo, ou seja, não se identificam tendências de aumento ou reduções significativas. As exceções são observadas no período de greves dos servidores técnico-administrativos no ano de 2014, e dos técnicos e professores em 2015.

Figura 2 - Relação Consumo x População UFBA-2000 a 2017

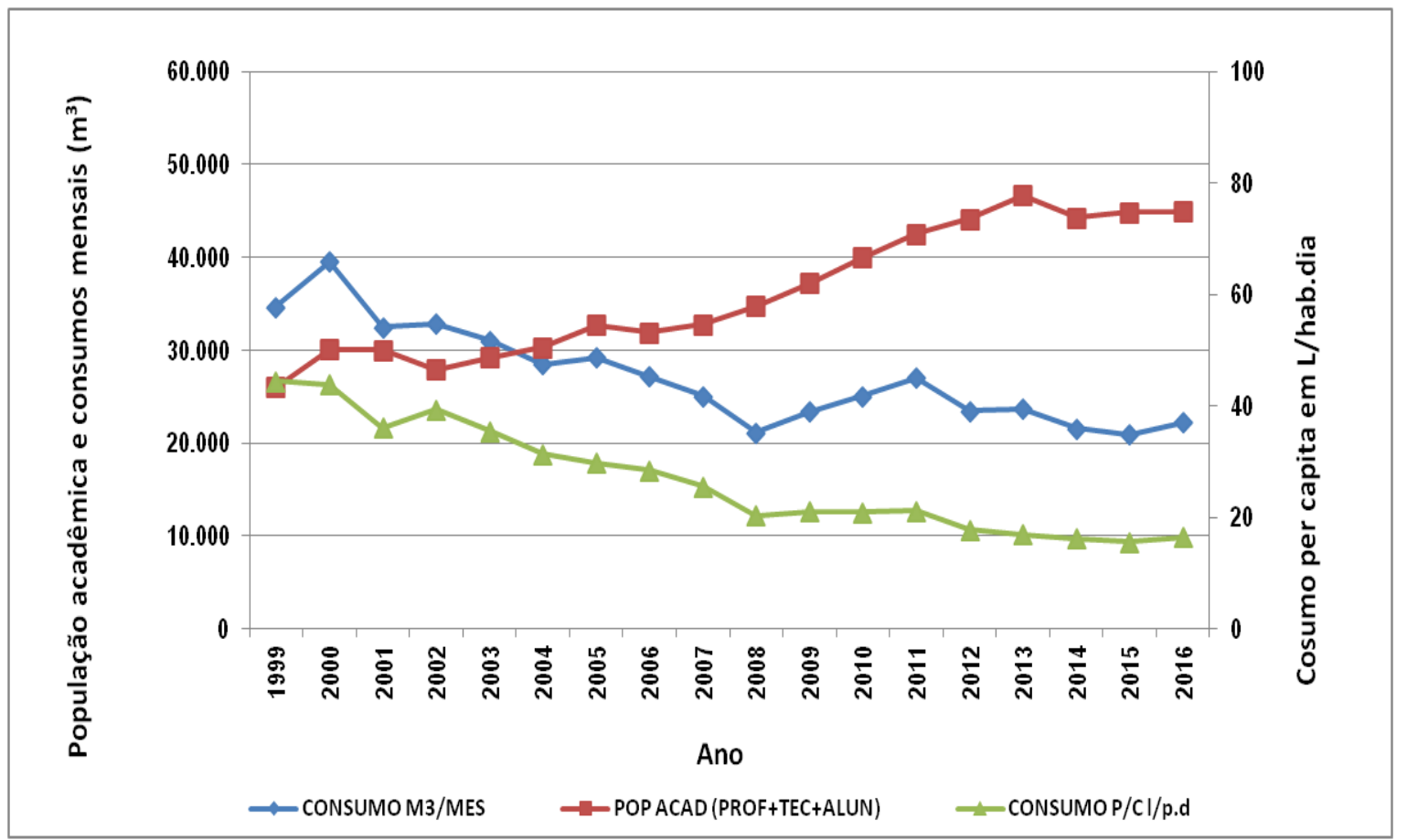

Fonte: AGUAPURA (www.teclim.ufba.br/aguapura, 2018), com base nos dados fornecidos pela Superintendência de Administração da UFBA e relatórios anuais da universidade.

Para uma melhor compreensão da evolução do consumo por pessoa, apresenta-se a Figura 3. Nesta, considera-se a evolução da população usuária como sendo a soma do total de discentes, docentes e técnicos administrativos. Observa-se que, durante a fase de construção de novos prédios, no âmbito do REUNI, mesmo se verificando um aumento do consumo total, 0 consumo per capita se manteve constante. Atribuise esse aumento à falta de controle do consumo de água por parte das construtoras que trabalharam nos campi (MARINHO; GONÇALES; KIPERSTOK, 2014). Contudo, a continuação das ações de monitoramento, acompanhamento e manutenção nos prédios em funcionamento normal permitiu que o consumo per capita ficasse estável.
Para interpretar se há relação entre o consumo praticado e o nível de percepção do consumo por parte da comunidade universitária, utilizaram-se os dados referentes ao lançamento dos consumos diários de consumo, no sistema Aguapura-Vianet entre 2015 e 2018. Mesmo se entendendo que o simples lançamento dos consumos não garante a sua percepção, a interpretação destes dados ajuda a compreender o nível de envolvimento da comunidade universitária no esforço de conservação da água (Figura 3).

Analisando, historicamente, a adesão das 88 Unidades da UFBA ao Sistema Vianet, construiuse a Figura 4, na qual se apresenta o número de leituras do hidrômetro inseridas mensalmente nos anos de 2005 a 2018. De acordo com os critérios de classificação disponibilizados pelo aplicativo, 
são consideradas como ótimas aquelas que registram mais de 22 leituras por mês. Se todas as Unidades realizassem, no mínimo, 22 lançamentos por mês, atingir-se-ia um total de 1936 lançamentos. Observe-se que a universidade como um todo nunca atingiu esse valor, vivenciando-se uma realidade aquém da esperada pela equipe de pesquisadores, para uma comunidade acadêmica.

O Programa considera como desempenho regular as Unidades que realizam entre 15 e 22 lançamentos por mês, o que daria para o conjunto das Unidades entre 1320 e 1936 lançamentos; e entende-se como uma participação precária um lançamento inferior a 15 por mês.

A maior quantidade de lançamentos se deu nos meses de junho a agosto de 2010. Nesse período ocorreu um crescimento no número de estudantes bolsistas de iniciação científica e inserção social no Programa Aguapura, envolvidos no acompanhamento e estímulo ao lançamento de dados e sua interpretação. Houve, também, uma renovação dos gestores do Programa, nas Unidades. Mesmo assim, o número total de lançamentos apenas atingiu o valor que separa as categorias de acompanhamento precário e regular.
Para ilustrar a dependência entre 0 lançamento das medições diárias nas Unidades e o trabalho de supervisão e estímulo desenvolvido pelos pesquisadores bolsistas de graduação do Programa, identificou-se em vermelho, na Figura 3 , a queda no número de lançamentos, verificada a partir de junho de 2017. Nesse momento, o Programa de pesquisa Aguapura desvinculou-se das instâncias administrativas da universidade, por motivos que não cabem aqui aprofundar, deixando de se comunicar diretamente com as Unidades.

Para ilustrar o perfil de adesão das Unidades da UFBA ao esforço de monitoramento diário do consumo de água, o Programa divulga, no site do Aguapura, gráficos como o apresentado na Figura 5. Nele, referente ao ano de 2017, se observa que apenas $18,2 \%$ das Unidades têm participação considerada como ótima e $35,2 \%$ sequer participam.

Assim, este artigo tem por objetivo apresentar e discutir alguns dos fatores que concorrem para definir o perfil de consumo de água predial, notadamente o acompanhamento e a percepção do consumo. Para tanto, foram definidos indicadores de consumo específico, aplicados no âmbito dos campi de Salvador e no âmbito predial em três Unidades, sendo estas analisadas comparativamente.

Figura 3 - Lançamento das medições de consumo no Programa AGUAPURA Vianet (2005 - 2018)

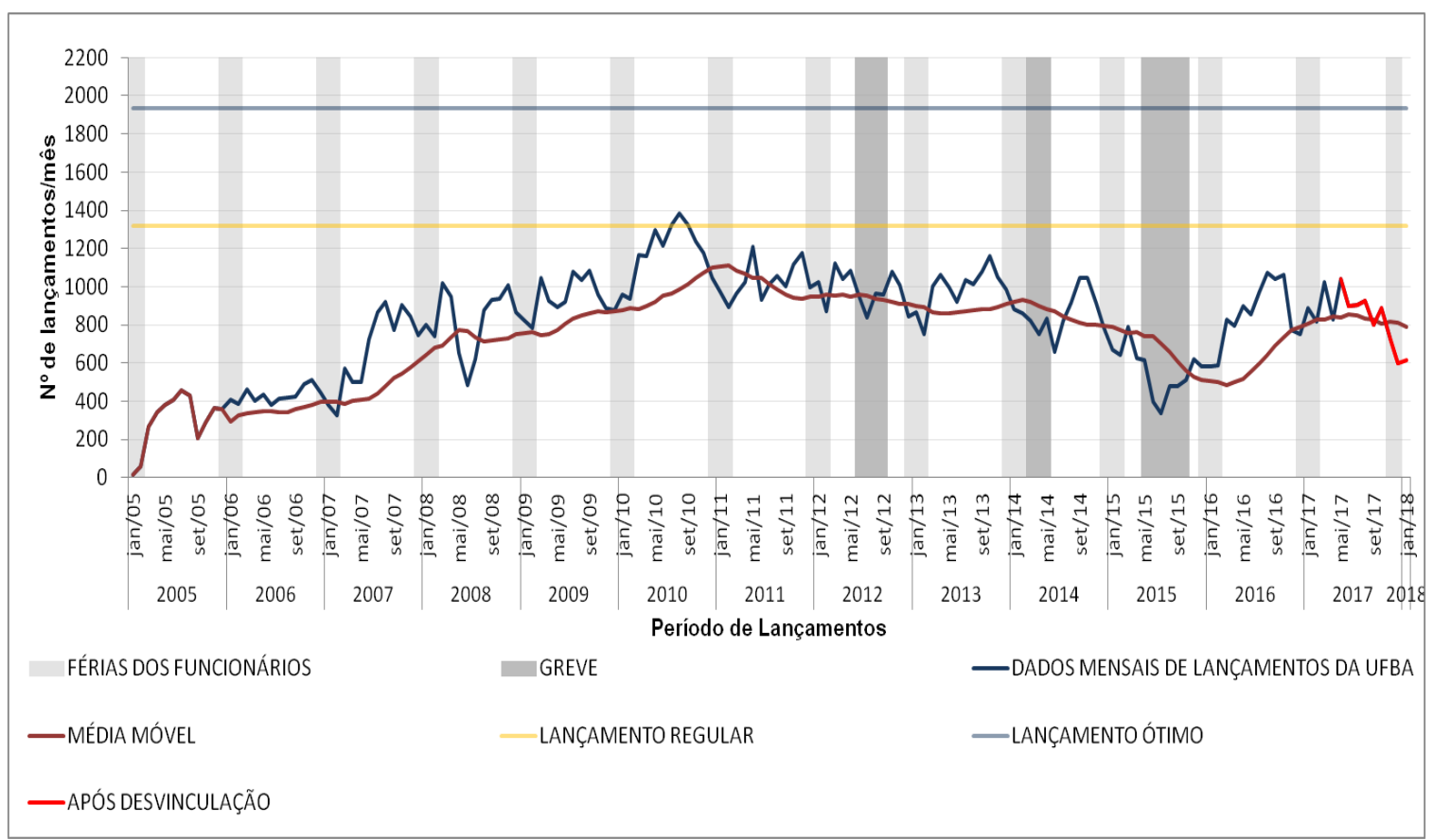

Fonte: AGUAPURA (www.teclim.ufba.br/aguapura, 2018). 
Figura 4 - Nível de participação das Unidades no lançamento dos consumos diários no sistema AGUAPURA-VIANET em 2017

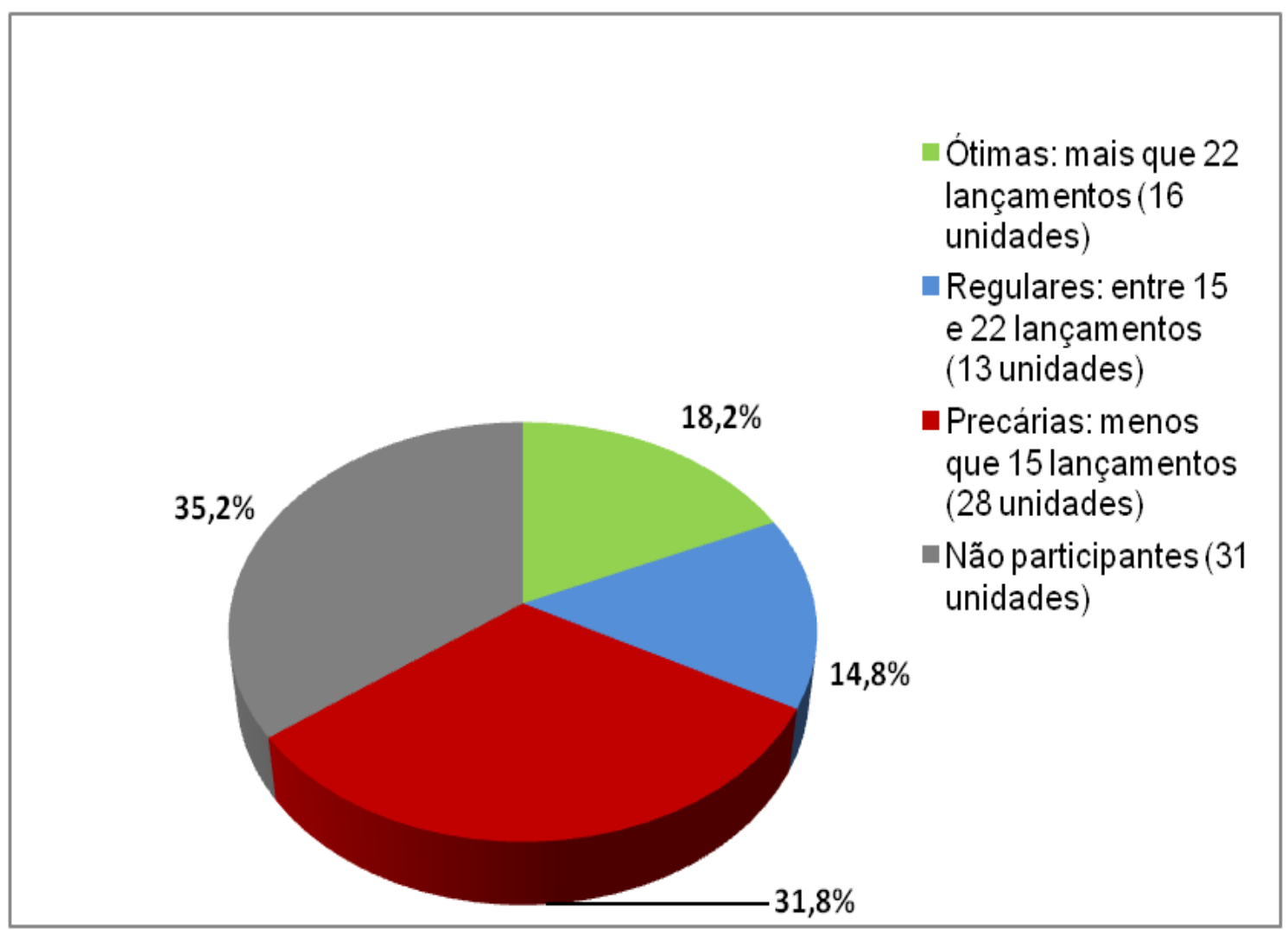

Fonte: AGUAPURA (www.teclim.ufba.br/aguapura, 2018)

\section{METODOLOGIA}

Para interpretar o consumo de água de edificações, é necessário se definir um marco conceitual que indique os diversos fatores que concorrem para tanto. Neste trabalho, se utiliza o marco conceitual desenvolvido e empregado pelo Programa Aguapura da Rede de Tecnologias Limpas, TECLIM, do Departamento de Engenharia Ambiental da Escola Politécnica da UFBA, apresentado na Figura 5. Analisa-se como o monitoramento e a percepção do consumo influenciam neste desempenho.

Em seguida, se apresenta a evolução do consumo geral dos campi da UFBA em Salvador, entre 1999 e 2018. Ao se analisar tal evolução, foi possível identificar como os fatores de controle e manutenção podem influenciar significativamente o perfil do consumo. Não se espera, contudo, com os dados disponíveis, que se possa discriminar quantitativamente a influência de cada um dos fatores indicados no marco conceitual da Figura 2, na evolução do consumo de água.
Após a apresentação do marco conceitual e contextualizado o consumo de água da UFBA, analisou-se comparativamente 0 consumo de água de três unidades universitárias, no ano de 2017: a Faculdade de Arquitetura, a Escola Politécnica e a Escola de Administração. Estas Unidades foram selecionadas por possuírem algumas características em comum e algumas diferenças claramente identificáveis. As três têm sido participantes ativas no registro do seu consumo no sistema Vianet (www.teclim.ufba.br/aguapura), que permite 0 acompanhamento diário do consumo de água dos prédios, bem como têm intensa atividade de ensino em salas de aula, sendo que a Politécnica dispõe de laboratórios com consumo significativo de água; consumo este que foi previamente estudado por Nakagawa (2008). Desta forma, pôde-se discriminar o consumo dos laboratórios separado do consumo das atividades de ensino e administrativas.

$\mathrm{Da}$ análise dos dados apresentados, obtiveram-se informações para melhor compreender o consumo de água em prédios 
universitários. Esta compreensão, claro, não esgota todos os fatores indicados no marco conceitual, nem abrange o consumo de outras unidades e serviços da universidade, o qual pode ser visto em outras publicações dos autores.

\section{MARCO CONCEITUAL PARA COMPREENSÃO DOS FATORES QUE INFLUENCIAM NO CONSUMO DE ÁGUA DE EDIFICAÇÕES}

O marco conceitual utilizado foi, gradativamente, construído ao longo de 20 anos de experiências desenvolvidas na implementação de projetos e programas de uso racional de água em edificações de uso público, incluindo a UFBA, prédios do governo do Estado da Bahia, shopping centers e instalações aeroportuárias (KIPERSTOK; KIPERSTOK, 2017). Conforme representado na Figura 5, o entendimento dos fatores que influenciam no consumo de água de uma edificação depende, em primeiro lugar, da qualidade do controle existente. Este controle se materializa a partir do monitoramento contínuo do seu consumo, da percepção dos usuários e gestores com relação ao consumo e da aplicação de mecanismos de estimulo ao consumo racional, como a cobrança pelo uso do recurso. O modelo reconhece quatro categorias de consumo: aquele que representa 0 objetivo precípuo do abastecimento, ou seja, o atendimento às necessidades ou desejos conscientes dos usuários; aquele que representa a água não aproveitada, seja no seu uso final, o desperdício, seja o que se dá no sistema hidráulico-sanitário dependente da qualidade, idade e manutenção das redes e equipamentos; a segregação de correntes de águas servidas para reuso; e o aproveitamento de fontes alternativas de menor impacto ambiental (KIPERSTOK, 2008 apud MARINHO, GONÇALES; KIPERSTOK, 2014).

\section{LEVANTAMENTO DE DADOS}

A evolução do consumo geral de água das três Unidades da UFBA estudadas foi consolidada a partir dos dados obtidos por meio das contas apresentadas pela EMBASA, concessionária responsável pelos serviços de abastecimento de água e coleta de esgotos sanitários, fornecidos pela Coordenação de Gestão Administrativa da Pró-Reitoria de Administração da UFBA.

O grau de participação das unidades acadêmicas no acompanhamento do seu consumo foi obtido a partir do número de inserções diárias do consumo de água no sistema Aguapura/Vianet. Aqui, não foram utilizados os dados referentes aos consumos diários, porque a base temporal de análise realizada foi a mensal. $O$ acompanhamento diário é um instrumento utilizado para o monitoramento e controle do consumo, visando a uma compreensão mais detalhada do desempenho de cada unidade, de maneira a permitir que medidas rápidas possam ser tomadas para responder a eventos de perdas e desperdícios.

Para a comparação do consumo entre as unidades estudadas, usou-se o indicador de consumo diário, em litros, por pessoa equivalente. Este foi calculado a partir da metodologia definida por Nakagawa (2008), na qual o usuário integral é aquele que passa 8 horas/dia durante 5 dias/semana. Para cada tipo de usuário, foi atribuído um coeficiente calculado pela razão entre a carga horária do indivíduo na unidade e o tempo de 40 horas. Exemplificando: um funcionário que possui a carga horária de 40 horas é atribuído o coeficiente igual a 1 , já um outro funcionário de 20 horas possui o coeficiente igual a 0,5 . Para os alunos, o coeficiente é calculado a partir do tempo de duração da aula dividido pelas 40 horas. $O$ valor encontrado é multiplicado pelo fator de frequência 0,75 que corresponde à frequência mínima para que o aluno não seja reprovado na disciplina. Obteve-se a População Consumidora Equivalente (PE) a partir do somatório da quantidade de vagas ofertadas para cada disciplina e da quantidade de funcionários da Unidade multiplicado pelos seus respectivos coeficientes.

Para o cálculo dos pagamentos referentes às contas de água em 2017, devido aos ajustes periódicos das tarifas da EMBASA, foi utilizada a tarifa de 2016 para o período de janeiro a maio de 2017, e a tarifa de 2017 para os outros meses desse ano.

\section{RESULTADOS}

\section{ANÁLISE COMPARATIVA DO CONSUMO DE ÁGUA ENTRE UNIDADES DA UNIVERSIDADE: OS CASOS DA ESCOLA DE ADMINISTRAÇÃO, DA POLITÉCNICA E A FACULDADE DE ARQUITETURA.}

Para se avançar nos esforços com vistas à conservação de água predial, é importante se 
definir metas de consumo, orientadas por indicadores que permitam uma comparação de desempenhos entre as unidades. A partir de 2016, - programa Aguapura procurou desenvolver mecanismos para acordar com as unidades universitárias metas específicas adequadas aos seus respectivos perfis. Utilizou-se o indicador de consumo por pessoa equivalente ao apresentado, sinteticamente, na metodologia deste artigo.

Visando ao aprimoramento desse indicador e sua aplicação como instrumento de gestão de programas de conservação de água predial, realizaram-se estudos comparativos de caso envolvendo unidades da UFBA. Neste trabalho, se apresentam os casos das Escolas de Administração e Politécnica e da Faculdade de Arquitetura, no ano de 2017.

Essas unidades possuem bons históricos de participação no Programa. De acordo com os dados obtidos no Aguapura/Vianet (www.teclim.ufba.br/aguapura, 2018) durante o ano de 2017, Administração e Politécnica realizaram uma média de 30 inserções/mês, enquanto que Arquitetura, uma média de 25 lançamentos/mês. As três unidades possuem direções e corpos administrativos engajados com o Programa, preocupados não apenas em inserir os dados, mas atentos à sua consistência e interpretação.

Nos três edifícios considerados neste estudo, ocorrem atividades acadêmicas, como aulas de graduação, pós-graduação e núcleos de pesquisa e extensão, e trabalhos administrativos. Realizamse, também, lavagem de carros com uso de baldes e, durante os finais de semana, há aulas, palestras e seminários. Quanto à rega dos jardins, a Escola de Administração e a Faculdade de Arquitetura utilizam mangueira, e esta última pratica tal atividade durante três vezes na semana. $\mathrm{Na}$
Politécnica, os jardins não são regados; recebem água somente nos dias chuvosos.

A lavagem dos pisos da Politécnica e da Arquitetura é feita com o uso de baldes uma vez por semana e diariamente, respectivamente, enquanto a Escola de Administração, somente uma vez por mês, com o uso de panos, pois o piso da Unidade não pode receber volumes maiores de água. Dentre as Unidades estudadas, a Politécnica é a única que possui nos seus laboratórios equipamentos que consomem água de forma significativa. Com relação ao consumo de água na irrigação de gramados na UFBA, identificou-se que este não se relaciona, necessariamente, com uma necessidade dos plantios, pois há uma técnica definida, mas com desperdícios significativos, como foi verificado na análise de consumo do campo de futebol do Centro de Esportes (SANTOS et al., 2018)

Este trabalho não se aprofunda nas causas que promovem o consumo, mas nas finalidades, das três unidades. Procurou-se, apenas, uma aproximação comparativa dos consumos praticados de forma a permitir uma reflexão dos gestores das unidades e, na sequência, a investigação das causas. $\mathrm{Na}$ concepção do Aguapura, este esforço deve ser de responsabilidade de cada unidade.

O consumo diário, populações equivalentes e consumo per capita das unidades se encontram na Tabela 1.

Avaliando as características e as atividades desenvolvidas nos prédios analisados, seria de se esperar que a Escola Politécnica apresentasse um maior consumo per capita devido à utilização de equipamentos especiais, como destiladores, nos seus laboratórios (ver Figura 6). Observa-se que nas outras Unidades não foram identificados equipamentos que demandem grandes quantidades de água.

Tabela 1 - Média mensal do consumo diário e por consumidor equivalente do ano de 2017

\begin{tabular}{cccc}
\hline & $\begin{array}{c}\text { População Consumidora } \\
\text { Equivalente }\end{array}$ & $\begin{array}{c}\text { Média mensal do consumo } \\
\text { diário }\left(\mathbf{m}^{\mathbf{3}} \mathbf{d i a}^{-1}\right)\end{array}$ & $\begin{array}{c}\text { Consumo per capita } \\
\left(\mathbf{L} \text { hab }^{-1} \text { dia-1) }\right.\end{array}$ \\
\hline $\begin{array}{c}\text { Escola de } \\
\text { Administração }\end{array}$ & 849 & 8 & 9,4 \\
\hline Escola Politécnica & 1415 & 14 & 9,9 \\
\hline $\begin{array}{c}\text { Faculdade de } \\
\text { Arquitetura }\end{array}$ & 485 & 8 & 16,5 \\
\hline
\end{tabular}

Fonte: Produção dos próprios autores. 
Figura 5 - Fatores que influenciam o consumo de água e energia em edificações.

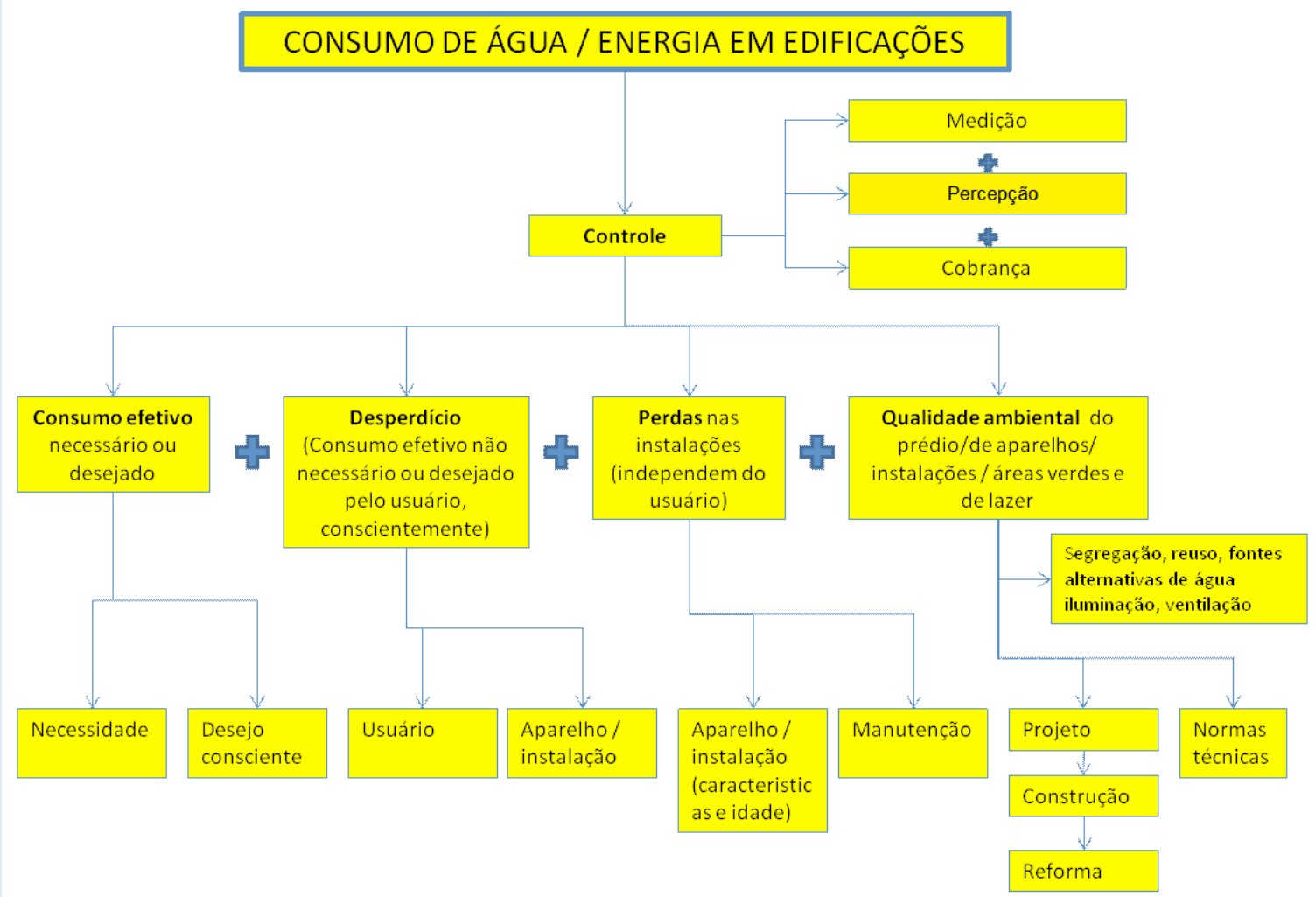

Fonte: KIPERSTOK, 2008.

Figura 6 - Consumo per capita da Escola de Administração, Politécnica (com destiladores) e da Faculdade de Arquitetura no ano de 2017

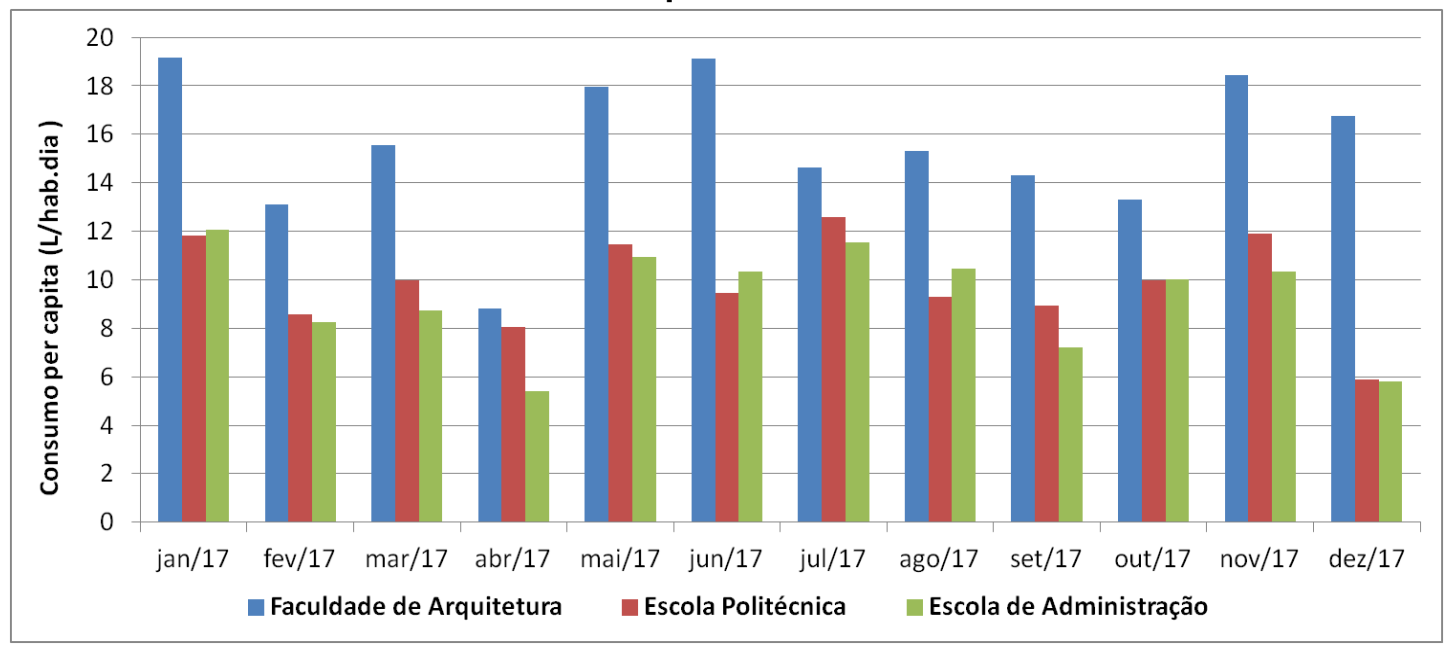

Fonte: Produção dos próprios autores.

Segundo Nakagawa (2008), os seis destiladores em operação na Politécnica, na época, consumiam, aproximadamente, $50 \mathrm{~m}^{3}$ mês $^{-1}$ ou $1,67 \mathrm{~m}^{3} \mathrm{dia}^{-1}$, o que representa $11 \%$ do consumo da unidade. O autor também observou que este consumo expressivo era devido à falta de uma regulagem adequada dos equipamentos, que apresentavam relações de água consumida por 
água destilada de 5 a 10 vezes maiores às especificadas pelos fabricantes.

Mesmo com o consumo atribuído aos destiladores, a Escola Politécnica apresentou, em 2017, um consumo per capita médio apenas 5\% superior ao da Escola de Administração, e com relação à Arquitetura, em torno de 2/3 da média consumida por aquela faculdade.

Para permitir a comparação do consumo da Politécnica com as outras unidades, retirou-se o que seria o consumo dos destiladores. Na Figura 7, se observa que a Politécnica apresenta o menor consumo per capita das três unidades, em dez dos doze meses do ano.

Quanto aos custos econômicos, devido ao consumo de água, referentes às três unidades comparadas, conforme Tabela 2, no ano de 2017, as três unidades, juntas, representaram uma despesa mensal de quase 18 mil reais. Este valor se eleva para mais de 30.000 reais por mês se for agregada a taxa de esgotamento sanitário, considerando as tarifas praticadas em 2017. Para contextualizar esse valor dentro do total pago pelos serviços de água e esgoto em toda a UFBA, a despesa em 2017 foi de quase 7 milhões de reais. As unidades analisadas se situam no ranking de consumo da instituição: $14^{\circ}$, $24^{\circ}$ e $27^{\circ}$ lugares, para a Politécnica, Arquitetura e Administração, respectivamente.

Os valores pagos por pessoa equivalente, nessas unidades, variaram entre 9,60 e 16,00 Reais por mês.

O maior dos consumos praticados nessas escolas, $16 \mathrm{~L} \mathrm{hab}^{-1} \mathrm{dia}^{-1}$, representa apenas 32\% do valor normalmente utilizado para calcular a demanda de água deste tipo de edificação, que é de 50 L/hab.dia (TOMAZ, 2000). Isto pode induzir a se pensar que estaria se praticando consumo bastante conservador. Os valores da demanda nos projetos de hidráulica das edificações servem para o dimensionamento de reservatórios e tubulações, mas não devem ser considerados como parâmetro para se orientar programas de conservação de água em universidades.

Se usarmos como referência os consumos da Escola Politécnica e da de Administração, pode-se observar que na Faculdade de Arquitetura existe margem para redução do consumo e despesa de, em torno, 40\%. Quando comparado o consumo praticado em 2014 ao dos anos anteriores ao início do Programa Aguapura, Marinho, Gonçalves e Kiperstok (2014) identificaram uma economia de aproximadamente $\mathrm{R} \$ 250.000 /$ mês.

\section{Figura 7 - Consumo per capita da Escola de Administração, Politécnica (sem destiladores) e da Faculdade de Arquitetura no ano de 2017}

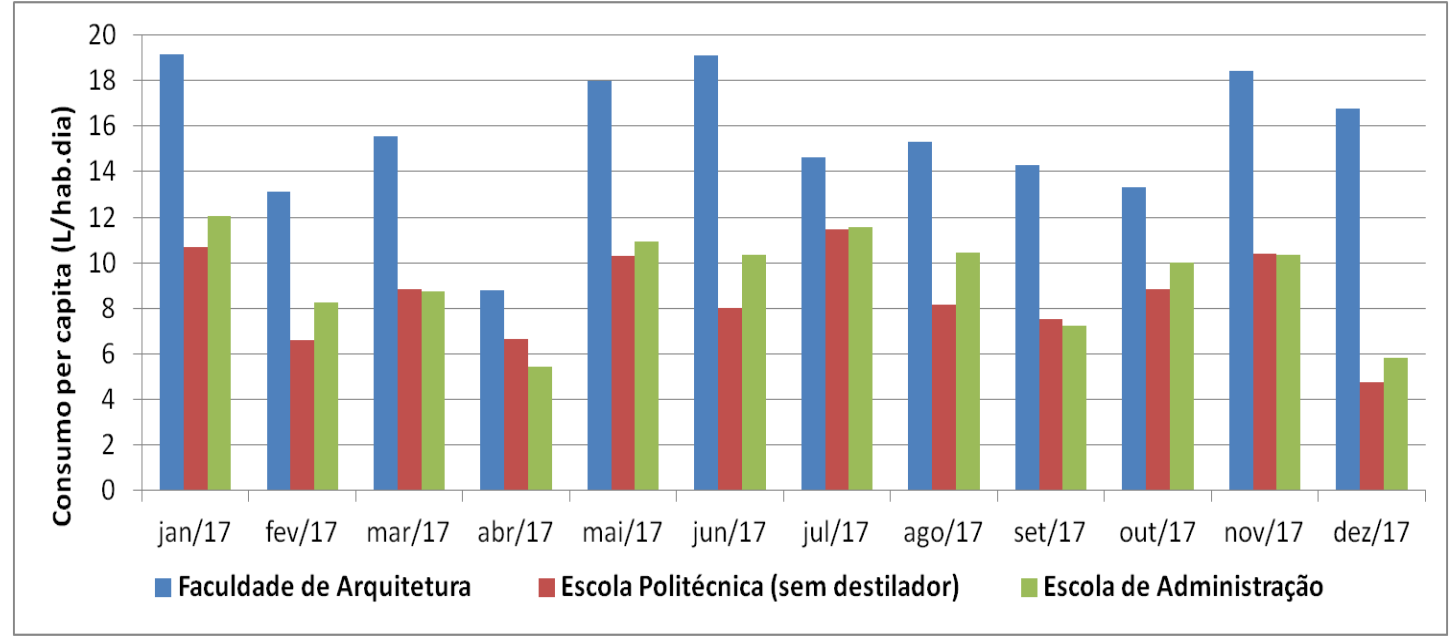

Fonte: Produção dos próprios autores.

\section{CONCLUSÃO}

Os resultados apresentados apontam para a influência que as práticas intensivas de monitoramento do consumo de água provocam na conservação predial. Contudo, para que possam ser atingidos melhores resultados, devem-se promover comparações que permitam aos usuários e gestores perceberem o desempenho das Unidades que frequentam e operam.

Estas comparações não são de fácil implementação, dada a quantidade de variáveis 
que concorrem para a definição do consumo predial. Para poder se comparar o consumo entre instituições, neste trabalho, se utilizou o indicador de consumo diário por população total, representada pela simples soma de todos os membros da comunidade registrada na universidade.

$\mathrm{Na}$ UFBA, em 2017, este valor foi um pouco inferior a $20 \mathrm{~L} \mathrm{hab}^{-1} \mathrm{dia}^{-1}$. Entre 1999 e 2000, atingia valor superior a $35 \mathrm{~L} / \mathrm{hab}$.dia. Mas, para se incentivar um maior comprometimento da comunidade acadêmica com a conservação d'água, deve se permitir a comparação do desempenho entre as unidades que a constituem. Para tanto, devem se utilizar indicadores mais adequados, que sejam sensíveis às características das unidades acadêmicas. Neste trabalho, foi utilizado o consumo por pessoa equivalente, que procura normalizar o consumo dos usuários com o que seria praticado por um usuário que permaneça na edificação oito horas por dia durante 5 dias por semana.

Uma comparação deste tipo para a Escola Politécnica, a Escola de Administração e a Faculdade de Arquitetura mostra que os consumos praticados foram entre 9 e $16 \mathrm{~L} \mathrm{hab}^{-1} \mathrm{dia}^{-1}$. Tais resultados permitem inferir a existência de um grande potencial de redução do consumo nas unidades estudadas e na universidade como um todo.

\section{REFERÊNCIAS}

KIPERSTOK, A. Racionalização do uso de água e energia nos prédios públicos do Governo do Estado da Bahia. Proposta apresentada pelo TECLIM/UFBA, documento interno, 2008.

; KIPERSTOK, A. C. Technology improvements or influencing user behaviour for water savings in administrative and university buildings: which one should come first? Frontiers in Civil Engineering, v. 2, p. 153201, 2017.

NAKAGAWA, A. K. Caracterização do consumo de água em prédios universitários: o caso da UFBA. 2008. 207p. Dissertação (Mestrado) - Escola Politécnica, Universidade Federal da Bahia, Salvador, 2008.

MARANHÃO, J. D.; PASSOS, W. D. S.; BAPTISTA, C. M.; VERAS, R. M. Adesão da UFBA ao REUNI e a nova modalidade curricular: os bacharelados interdisciplinares. Trabalho apresentado no VI Colóquio Internacional de Políticas e Práticas curriculares, Salvador, 2014.

MARINHO, M.; GONÇALVES, M. DO S; KIPERSTOK, A. Water conservation as a tool to support sustainable practices in a Brazilian public university. Journal of Cleaner Production, v. 62, p. 98-106, 2014.

SANTOS, A. L. O. A, et al. Desperdício de água na irrigação de campos de futebol em universidades: o caso da universidade federal da Bahia. Trabalho apresentado no Congresso da UFBA - Pesquisa, ensino e extensão. Salvador, 2018.

TOMAZ, P. Previsão de consumo de água. Interface das instalações prediais de água e esgoto com os serviços públicos. São Paulo: Comercial Editora Hermano \& Bugelli Ltda, 2000. 